\title{
Protein tyrosine phosphatase receptor-type $\delta$ acts as a negative regulator suppressing breast cancer
}

\author{
Xiaotang Yu ${ }^{1, *}$, Fan Zhang ${ }^{2, *}$, Jun Mao ${ }^{1}$, Ying Lu ${ }^{1}$, Jiazhi Li ${ }^{1}$, Wei Ma ${ }^{3}$, Shujun Fan ${ }^{1}$, \\ Chunying Zhang ${ }^{1}$, Qing Li ${ }^{1}$, Bo Wang ${ }^{1}$, Bo Song ${ }^{1}$ and Lianhong $\mathrm{Li}^{1}$ \\ ${ }^{1}$ Department of Pathology and Forensic Medicine, Dalian Medical University, Dalian 116044, PR China \\ ${ }^{2}$ Department of General Surgery, The Second Affiliated Hospital of Dalian Medical University, Dalian 116044, PR China \\ ${ }^{3}$ Department of Human Anatomy, Dalian Medical University, Dalian 116044, PR China \\ "These authors have contributed equally to this work \\ Correspondence to: Lianhong Li, email: lilianhong917@126.com \\ Keywords: protein tyrosine phosphatase receptor-type $\delta$; signal transducer and activator of transcription 3; breast cancer stem \\ cells; epithelial-mesenchymal transition; interleukin-6 \\ Received: February 15, $2017 \quad$ Accepted: October 03, $2017 \quad$ Published: October 24, 2017 \\ Copyright: Yu et al. This is an open-access article distributed under the terms of the Creative Commons Attribution License 3.0 (CC \\ BY 3.0), which permits unrestricted use, distribution, and reproduction in any medium, provided the original author and source are \\ credited.
}

\section{ABSTRACT}

Protein tyrosine phosphatase receptor-type $\delta$ (PTPRD) is frequently inactivated in human cancers. This study investigated the role of PTPRD in the regulation of stemness, epithelial-mesenchymal transition (EMT), and migration and invasion in breast cancer cells. In vitro, PTPRD silencing using siRNA enhanced the stem cell-like properties of breast cancer cells, including their mammosphere- and holoclone-forming abilities, and it promoted tumorigenicity in vivo. PTPRD knockdown also increased the CD44+/CD24- breast cancer stem cell (BCSC) population and the expression of the stem cell markers ALDH1 and OCT4. It also promoted migration and invasion by breast cancer cell, EMT, and activation of signal transducer and activator of transcription 3 (STAT3). BCSCs expressed low levels of PTPRD, displayed mesenchymal phenotypes, and were more sensitive to IL-6-mediated STAT3 activation than non-BCSCS. PTPRD expression was upregulated by IL-6 in breast cancer cells, thereby establishing a negative feedback circuit by which IL-6 induced canonical STAT3 phosphorylation and transiently upregulated PTPRD, which in turn dephosphorylated STAT3 and prevented downstream signaling via the IL-6/STAT3 cascade. These data suggest that therapies aimed at restoring or enhancing PTPRD expression may be effective in controlling breast cancer progression and metastasis.

\section{INTRODUCTION}

Breast cancer is a significant health problem worldwide, accounting for an estimated 1.7 million new cases and 521,900 cancer-related deaths globally in 2012 [1]. Disease recurrence and metastasis are the main causes of death in breast cancer patients [2]. Histologically and molecularly, it is suggested that a small fraction of cells within tumors is responsible for cancer initiation, metastasis, relapse, and resistance to cancer therapy [3-7]. These cells are called cancer stem cells (CSCs) or cancer stem cell-like cells, and share many phenotypic and genotypic properties with somatic stem cells, such as the capacity for self-renewal and multi-potent differentiation ability. CSCs can be identified by various functional assays, including tumor sphere formation, xenograft assays, or detection of specific cell-surface markers [e.g., CD44, CD24, Oct-4, and ALDH1 in the case of breast cancer stem cells (BCSCs)] [8]. The mechanisms underlying CSC self-renewal and therapeutic resistance remain to be fully elucidated.

Protein tyrosine phosphatase receptor-type $\delta$ (PTPRD) is composed of a cell adhesion moleculelike extracellular domain and two cytoplasmic protein 
tyrosine phosphatase domains [9]. The PTPRD gene is frequently inactivated in various human cancers, including lung, colorectal, and breast cancers, glioblastoma, clear cell renal cell carcinoma, and melanoma [10-16]. Inactivating mechanisms include homozygous or heterozygous deletion, microsatellite alterations, and epigenetic silencing, suggesting that PTPRD is a tumor-suppressor gene [14, 16-19]. Whole exome sequencing data of 510 breast cancer specimens highlighted PTPRD as one of the most significantly mutated genes [15]. PTPRD alterations occurred in $7 \%$ of all breast cancer cases $[15,20]$, and the mutant $P T P R D$ variant was associated with high frequencies of mutation in other genes [20]. In addition, PTPRD has been found to be hypermethylated in breast cancer cell lines and tissue specimens [19]. Despite the high prevalence of PTPRD inactivation in breast cancer and other tumors, the role of PTPRD in tumor progression is not yet fully understood. A previous study reported that phosphorylated signal transducer and activator of transcription 3 (pSTAT3) is a substrate of PTPRD. Accordingly, cancer-specific PTPRD mutations abrogated the ability of the phosphatase to dephosphorylate STAT3, leading to aberrant STAT3 activation and promotion of glioma development [18]. On the other hand, studies showed that STAT3 signaling is required for the growth of CD $44^{+} / \mathrm{CD} 24^{-}$stem cell-like breast cancer cells [21-23]. STAT3 is a latent cytoplasmic transcription factor that serves dual functions as a signal transducer and activator of transcription, and can be activated by interleukin-6 (IL-6) and epidermal growth factor receptor (EGFR) [24]. Once phosphorylated (pSTAT3), STAT3 becomes activated, dimerizes, and translocates into the cell nucleus, where it activates gene transcription that maintains the stem cell pool, promotes cell growth and angiogenesis, and inhibits apoptosis and cell differentiation [25-28]. In addition, the IL-6/STAT3 signal pathway has been associated with induction of the epithelial-mesenchymal transition (EMT) process [29, 30].

Here we provide evidence for a negative feedback loop by which IL-6 induces canonical STAT3 phosphorylation and subsequently upregulates PTPRD, which in turn dephosphorylates STAT3 to restrain further signaling through the IL-6/STAT3 cascade. Moreover, our data suggests that low constitutive PTPRD expression in BCSCs may be a key determinant of the pluripotency and mesenchymal features of this unique population of cells.

\section{RESULTS}

\section{PTPRD knockdown enhances breast cancer cell stemness}

To define the molecular functions of PTPRD in breast cancer, we first performed transient small interference RNA (siRNA)-mediated PTPRD knockdown in MDA-MB-231 and MCF-7 cells (Figures 1A-1B). We then assessed the effects of PTPRD downregulation on $\mathrm{CD} 44^{+} / \mathrm{CD} 24^{-} \mathrm{BCSC}$ numbers as well as on their mammosphere- and holoclone-forming abilities. Results showed that the proportion of $\mathrm{CD} 44^{+} /$ CD24- BCSCs was significantly increased after PTPRD siRNA transfection (Figures 1C-1D). As mammosphere formation is a typical BCSC property reflecting the self-renewal potential of these cells [31], we carried out mammosphere formation assays that showed that PTPRD knockdown significantly increased the number and size of spheres formed by BCSCs derived from MCF-7 and MDA-MB-231 cells $(\mathrm{P}<0.01$; Figures $1 \mathrm{E}-$ $1 F)$. Holoclone formation is another typical property of CSCs [32]. We cultured BCSCs in monoclonal fashion after siRNA transfection (Figure 1G) and then counted the resulting holoclones, meroclones, or paraclones based on their different morphologies (Figure 1H). Holoclones appeared as clusters of homogeneously and tightly packed small cells with regular and smooth margins (Figure 1Ha) [32]. In contrast, paraclones consisted of dispersed, larger cells with fragmented borderlines (Figure 1Hc), while meroclones exhibited an intermediate morphology (Figure 1Hb). More and larger clones were formed by breast cancer cells transfected with PTPRD siRNA than by the cells transfected with NC siRNA ( $\mathrm{P}<0.01$; Figures $1 \mathrm{I}-1 \mathrm{~J})$. Also, the ratio of holoclones was significantly higher in the PTPRD knockdown group than in control cells $(\mathrm{P}<0.01$; Figure $1 \mathrm{~K})$.

At the protein level, PTPRD knockdown significantly increased the expression of the stemness markers ALDH1 and OCT-4, compared with BCSCs transfected with NC siRNA $(\mathrm{P}<0.05$; Figures $1 \mathrm{~L}-1 \mathrm{M})$.

\section{PTPRD knockdown promotes breast cancer cell migration, invasion, and epithelial-mesenchymal transition}

Proliferation and cell cycle distribution analyses in breast cancer cells showed no significant differences between PTPRD-knockdown and control cells (Supplementary Figures 1 and 2). In contrast, woundhealing assays indicated increased motility in PTPRDknockdown cells compared with control cells $(\mathrm{P}<0.05$; Figures 2A-2B). Transwell assays, on the other hand, showed that migration and invasion capacities were also significantly increased in cells transfected with PTPRD siRNA ( $\mathrm{P}<0.01$; Figures $2 \mathrm{C}-2 \mathrm{E})$. These data clearly indicate that downregulation of PTPRD promotes migration and invasion in breast cancer cells.

Next, we analyzed the effect of PTPRD silencing on EMT markers using western blot. Consistent with EMT induction, the expression of the epithelial marker E-cadherin was decreased, while the expression of the 


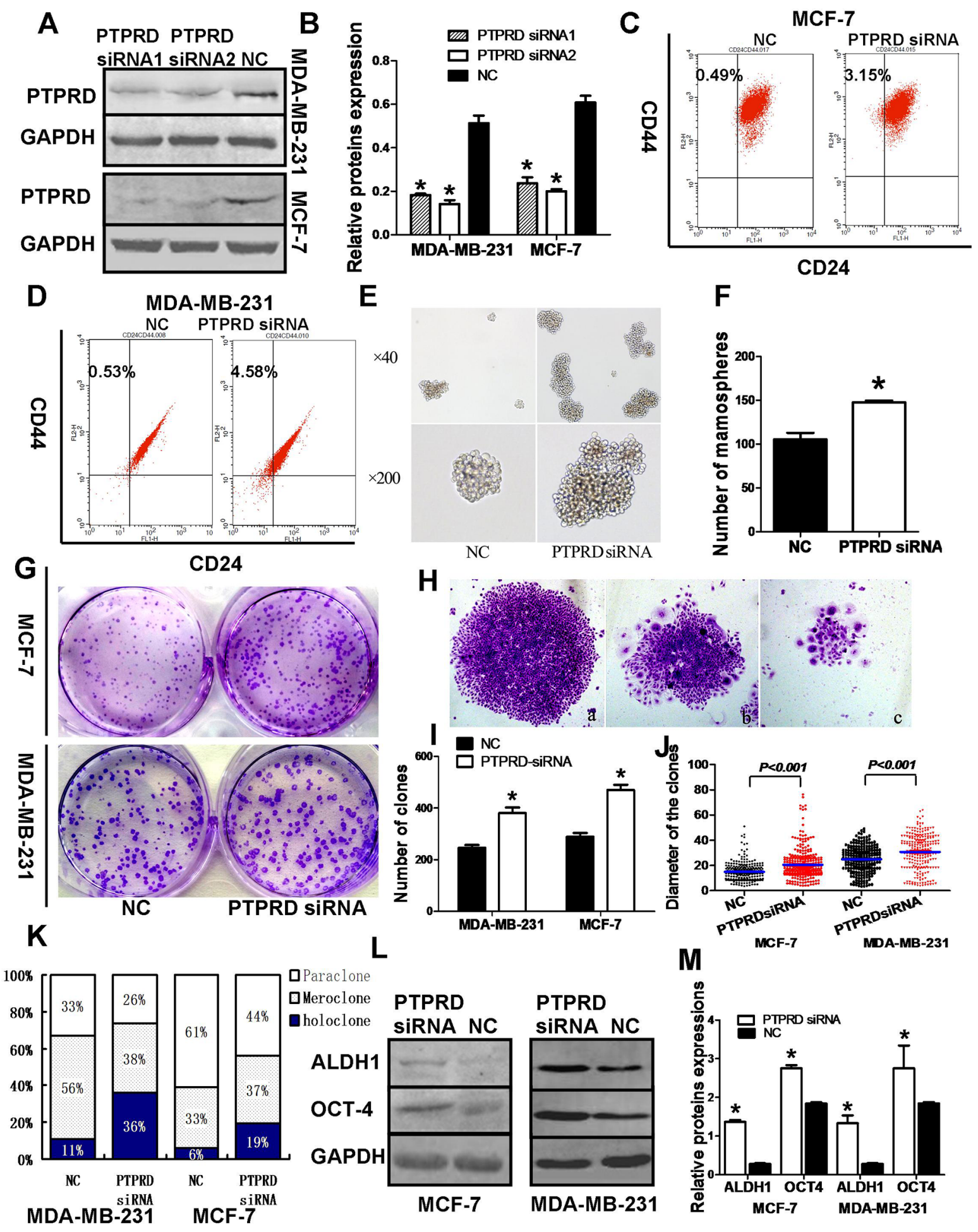

Figure 1: PTPRD knockdown promotes stem cell-like properties in breast cancer cells. MDA-MB-231 and MCF-7 breast cancer cells were transfected with PTPRD siRNA or negative control (NC) siRNA for $48 \mathrm{~h}$ and then subjected to different assays. (A) PTPRD expression in PTPRD-silenced and NC cells. (B) Quantification of western blot signals from A. (C-D) Fluorescence cell sorting of CD44 ${ }^{+} / \mathrm{CD} 24{ }^{-}$cells. (E) Mammosphere formation assay. (F) Mammosphere formation quantification $\left({ }^{*} \mathrm{P}<0.05\right)$. (G) Holoclone colony formation assay. (H) Clone morphologies: a, Holoclone, b, Meroclone, c, Paraclone. (I) Colony formation quantification. Histograms indicate mean clone numbers formed by 500 starting cells. (J) Clone diameter summary data. Each dot represents an individual clone; lines indicate median diameter. (K) Percentual distribution of holoclones, meroclones, and paraclones formed by PTPRD siRNA- and NC siRNA-transfected cells ( $\left.{ }^{*} \mathrm{P}<0.05\right)$. (L) Western blot analysis of stem cell markers ALDH1 and OCT-4. (M) Quantification of ALDH1 and OCT-4 levels from western blots like those shown in $\mathrm{L}\left({ }^{*} \mathrm{P}<0.05\right)$. 
mesenchymal marker vimentin was increased, in PTPRDsilenced cells $(\mathrm{P}<0.05$; Figures $2 \mathrm{~F}-2 \mathrm{G})$.

\section{PTPRD negatively regulates IL-6/STAT3 signaling}

The IL-6/STAT3 signaling pathway plays an important role in the regulation of stemness, EMT, and metastatic dissemination of cancer cells [21, 29, 30]. We therefore investigated whether the positive influence of
PTPRD on breast cancer cell stemness and EMT depends on IL-6/STAT3 signaling. Our results showed that PTPRD knockdown significantly increased pSTAT3 levels, without affecting total STAT3 (Figures 3A-3C). To further analyze this interaction, we first activated STAT3 by treating cells with IL-6 $(20 \mathrm{ng} / \mathrm{ml})$ in serum-free conditions and analyzed samples $3,6,12$, and $24 \mathrm{~h}$ later. We found that both pSTAT3 and PTPRD protein levels were significantly induced by IL-6 exposure (Figures 3D-3F). Specifically, PTPRD expression in both MDA-MB-231 and MCF-7
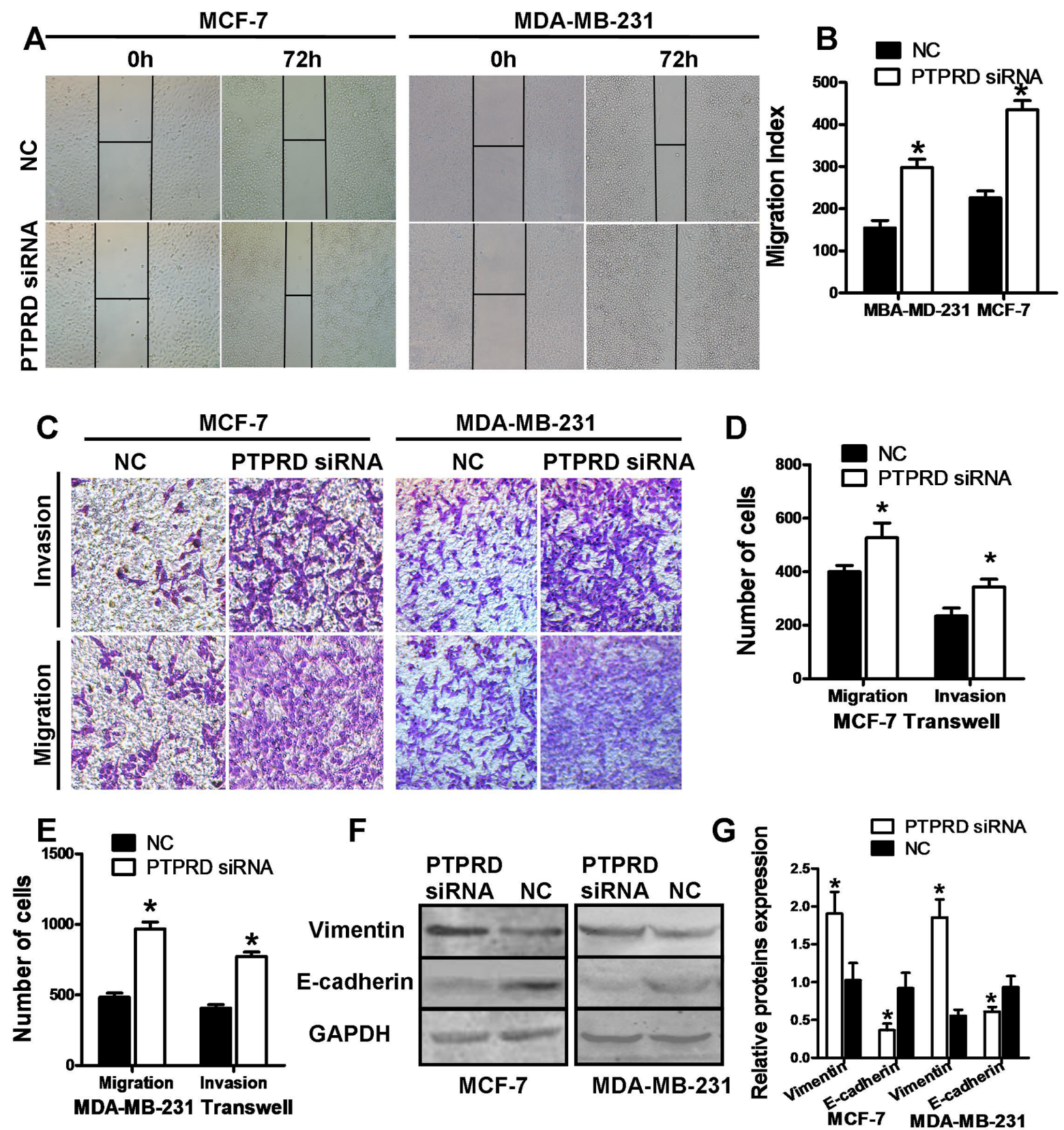

Figure 2: PTPRD knockdown increases migration and invasion in breast cancer cells. MDA-MB-231 and MCF-7 cells were transfected with PTPRD or NC siRNAs for $24 \mathrm{~h}$, and then subjected to different assays. (A) Representative microphotographs of the wound-healing assay. (B) Wound-healing assay quantification data. (C) Representative microphotographs of tumor cell migration and invasion assays. (D) Cell migration and invasion assay quantification of MCF-7. (E). Cell migration and invasion assay quantification of MDA-MB-231. (F) Western blot analysis of vimentin and E-cadherin expression. (G) Protein expression quantification from western blots like those shown in $\mathrm{F}$. 
breast cancer cells increased significantly 12 to $24 \mathrm{~h}$ after IL-6 treatment. PTPRD mRNA levels were also increased in IL-6-treated cells (Figure 3G).

Concomitantly, IL-6 exposure increased the expression of the stem cell markers OCT-4 and ALDH1 in cells, and suggested EMT activation by increasing vimentin and repressing E-cadherin expression (Figures 3H-3I).

These results provide evidence that IL-6 induces relatively rapid and transient PTPRD expression, suggesting a potential role for PTPRD as a negative feedback regulator of IL-6/STAT3 signaling. To test this possibility, we evaluated IL-6-mediated STAT3 phosphorylation in both control and PTPRD-silenced breast cancer cells. Indeed, western blot results showed relatively higher pSTAT3 levels in PTPRD-knockdown cells (Figures 3H-3I). In addition, increased levels of ALDH1, OCT-4, and vimentin, and decreased E-cadherin expression, were observed in IL-6-exposed, PTPRDknockdown cells compared with PTPRD-competent cells similarly stimulated with IL-6 (Figures $3 \mathrm{H}-3 \mathrm{I}$ ).

These data suggest that PTPRD is an IL-6-induced negative-feedback regulator that prevents overactivation of the IL-6/STAT3 signaling pathway.

\section{BCSCs express low PTPRD levels and are more sensitive to IL-6 stimulation}

To assess the expression of PTPRD in $\mathrm{CD} 44^{+} /$ $\mathrm{CD} 24^{-}$BCSCs and in non-BCSCs, BCSCs were isolated from MDA-MB-231 cells by using magnetic beads. To eliminate the effect of cytokines and growth factors that may activate STAT3 and affect the expression of PTPRD, the cells were serum-starved for $24 \mathrm{~h}$ before isolation. Expression of the stem cell markers ALDH1 and OCT4 was then detected using western blotting to assure successful isolation of BCSCs. Our data confirmed that $\mathrm{CD} 44^{+} / \mathrm{CD} 24^{-}$BCSCs expressed significantly elevated levels of ALDH1 and OCT-4 (Figures 4A-4B). Endogenous PTPRD and STAT3 mRNA expression was then estimated by qRT-PCR. Results showed that BCSCs expressed significantly lower levels of PTPRD mRNA compared with non-BCSCs, while STAT3 mRNA levels were similar in both cell types (Figure 4C). Furthermore, we profiled the expression of PTPRD, STAT3/pSTAT3, E-cadherin, and vimentin in BCSCs and non-BCSCs using western blot. Consistent with mRNA results, data showed that PTPRD expression was downregulated in $\mathrm{CD}_{4} 4^{+} / \mathrm{CD} 24^{-} \mathrm{BCSCs}$, whereas levels of STAT3 and pSTAT3 were comparable for both BCSCs and non-BCSCs. In addition, expression of vimentin was significantly increased, while that of E-cadherin was decreased, in BCSCs compared to non-BCSCs, suggesting that these CSCs display mesenchymal characteristics (Figures 4A-4B). Immunofluorescence staining in cultured cells further confirmed reduced PTPRD expression in BCSCs (Figure 4D).
Because STAT3 signaling is more active in PTPRDsilenced cells, and BCSCs showed constitutively lower PTPRD levels, it was of interest to determine whether STAT3 activation in response to IL-6 occurs more readily in BCSCs than in non-BCSCs. To assess this, cells were starved for $24 \mathrm{~h}$, and then stimulated with IL-6 for 12 h. Then, BCSCs were isolated and the expression of pSTAT3 and PTPRD was measured by western blot in BCSCs and non-BCSCs. Results showed that pSTAT3 was significantly higher in BCSCs than in non-BCSCs (Figures $4 \mathrm{E}-4 \mathrm{~F})$. This result indicates that low baseline expression of PTPRD correlates with increased IL-6 sensitivity and enhanced STAT3 signaling in BCSCs.

\section{PTPRD silencing promotes tumor xenograft growth in vivo}

To assess the tumorigenic effect of PTPRD downregulation, we generated an in vivo breast cancer xenograft model by subcutaneously injecting breast cancer cells MDA-MB-231 that had been transfected with PTPRD shRNA or NC shRNA into the mammary glands of SCID mice. Tumor volume measurements showed that PTPRD downregulation significantly promoted xenograft formation and growth (Figures 5A-5B). On the other hand, western blotting and immunohistochemistry analyses indicated decreased PTPRD and increased pSTAT3 expression in samples from PTPRD shRNA-transfected breast cancer cells, compared with NC shRNA controls (Figures 5C-5E).

\section{DISCUSSION}

Although PTPRD inactivation is highly prevalent in various human cancers [33-36], its specific contribution to tumorigenesis remains poorly understood. Thus, the current study sought to investigate the signal transduction pathways influenced by PTPRD. Consistent with its previously ascribed role as a tumor-suppressor, we show that PTPRD downregulation enhances CSC marker expression and promotes migration, invasion, and EMT in breast cancer cells in vitro. Moreover, shRNA-mediated PTPRD silencing enhanced the growth of breast cancer cell xenografts in vivo. The present evidence suggests that these effects result from attenuation of IL-6/STAT3 signaling by PTPRD. Specifically, we show that in addition to mediating STAT3 activation, IL-6 induces the expression of PTPRD. This is the first study, to our knowledge, to report the effect of IL-6 on PTPRD expression. As our silencing experiments suggest, the consequence of the late increase in PTPRD after IL-6 exposure is repression of further STAT3 activation. Thus, PTPRD appears to act as a negative feedback regulator that balances IL-6/STAT3 pathway activity.

EMT is a process by which epithelial cells lose polarity and cell-cell contact, and acquire migration and 
A
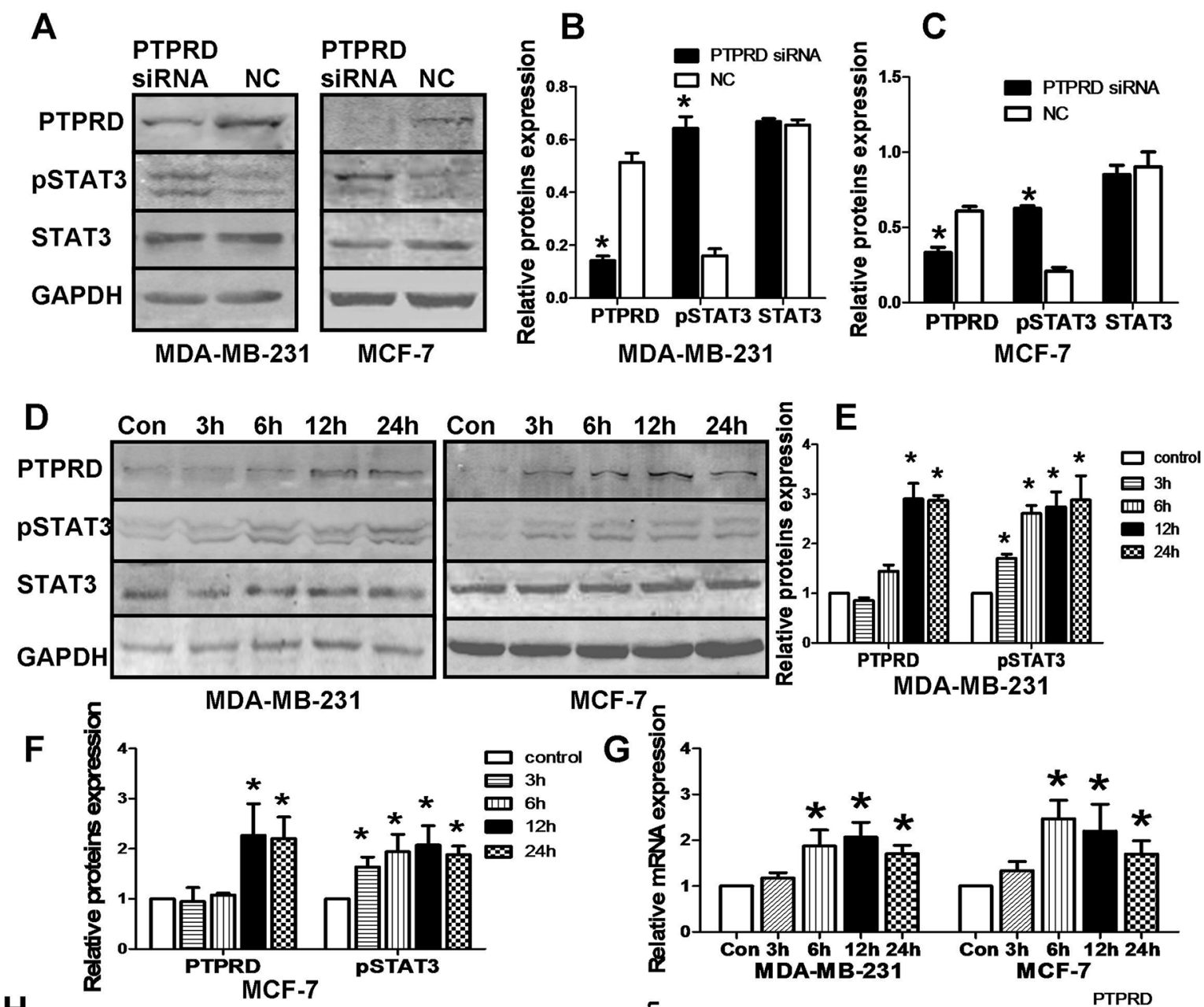

H
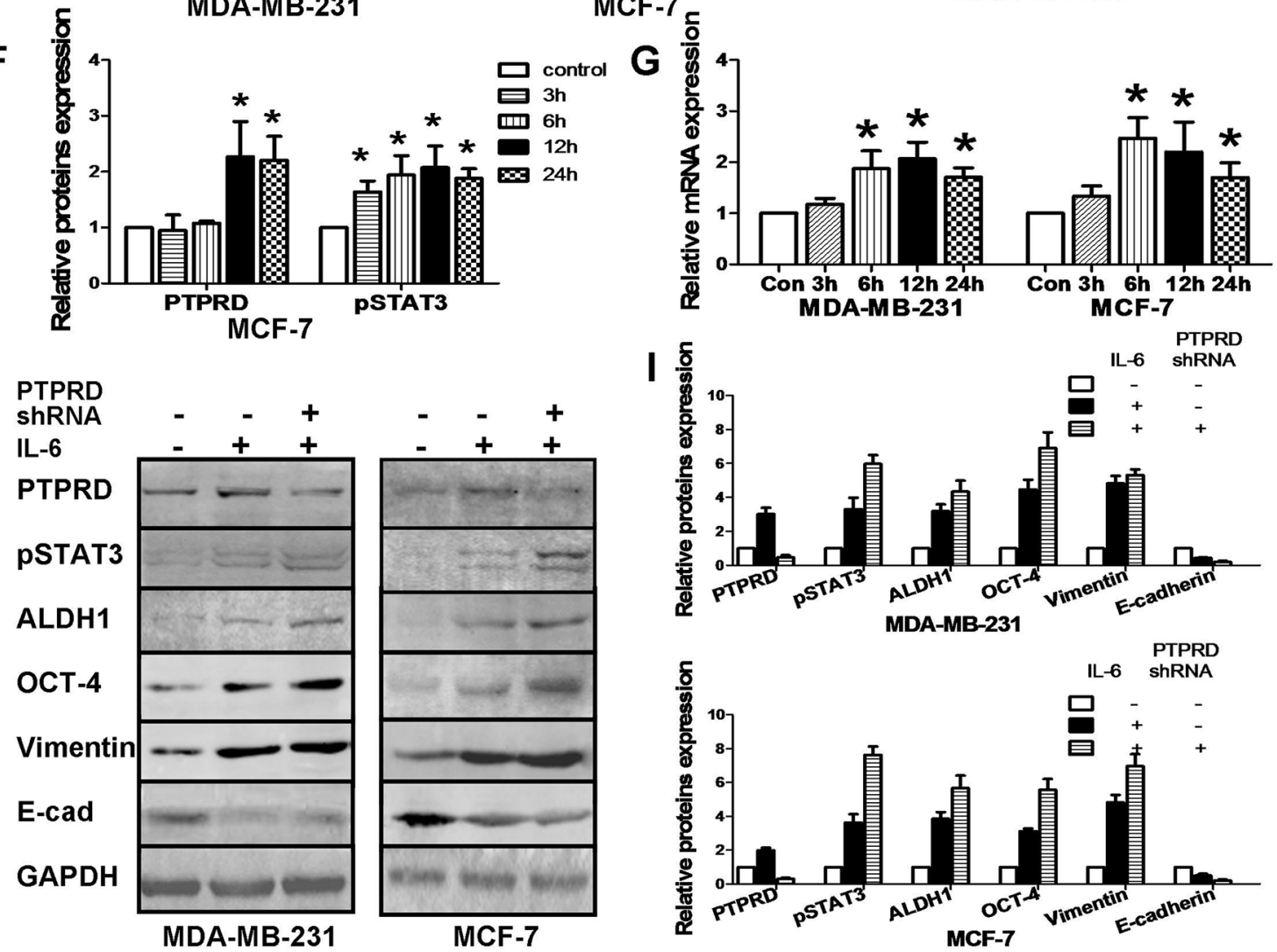

Figure 3: PTPRD regulates the IL-6/STAT3 signaling pathway. (A) Western blotting analysis of PTPRD, STAT3, and pSTAT3 in breast cancer cells transfected with PTPRD or NC siRNAs for $48 \mathrm{~h}$. (B-C) Quantification of western blot data from A ( $\left.{ }^{*} \mathrm{P}<0.05\right)$. (D) Western blot analysis of PTPRD, STAT3, and pSTAT3 in breast cancer cells treated with IL-6. (E-F) Quantification of western blot data from D. (G) Time course of PTPRD mRNA induction in IL-6-treated cells, determined by qRT-PCR ( $\left.{ }^{*} \mathrm{P}<0.05\right)$. (H) Western blot analysis of PTPRD, pSTAT3, and stemness and EMT markers in breast cancer cells transfected with PTPRD or NC shRNAs. IL-6 was added to cultures for $12 \mathrm{~h}$ (PTPRD and pSTAT3) or $48 \mathrm{~h}$ (vimentin, E-cadherin, ALDH1, and OCT4) before expression analyses. (I) Protein quantification from western blots like those shown in $\mathrm{H}\left({ }^{*} \mathrm{P}<0.05\right)$. 
invasion capacities characteristic of mesenchymal stem cells. EMT plays an important role in organ formation and cell differentiation, and occurs also during wound healing and tumor metastasis [37, 38]. Our current data showed that PTPRD downregulation significantly induced breast cancer cell EMT by promoting, in parallel with increased vimentin and decreased E-cadherin expression, their migratory and invasive capacities. The fact that PTPRD downregulation had no effect on breast cancer cell viability and cell-cycle distribution indicates that the tumor-suppressive role of PTPRD is mainly related to EMT downregulation. Our observations are consistent with two other studies. In colorectal cancer, PTPRD suppressed tumor cell migration by promoting cell-cell adhesion [17]. In glioma, loss of PTPRD expression accelerated tumor formation, but did not affect cell proliferation [18].

The molecular mechanisms underlying PTPRD regulation of BCSCs properties and EMT remain to be determined. PTPRD acts on several substrates, including

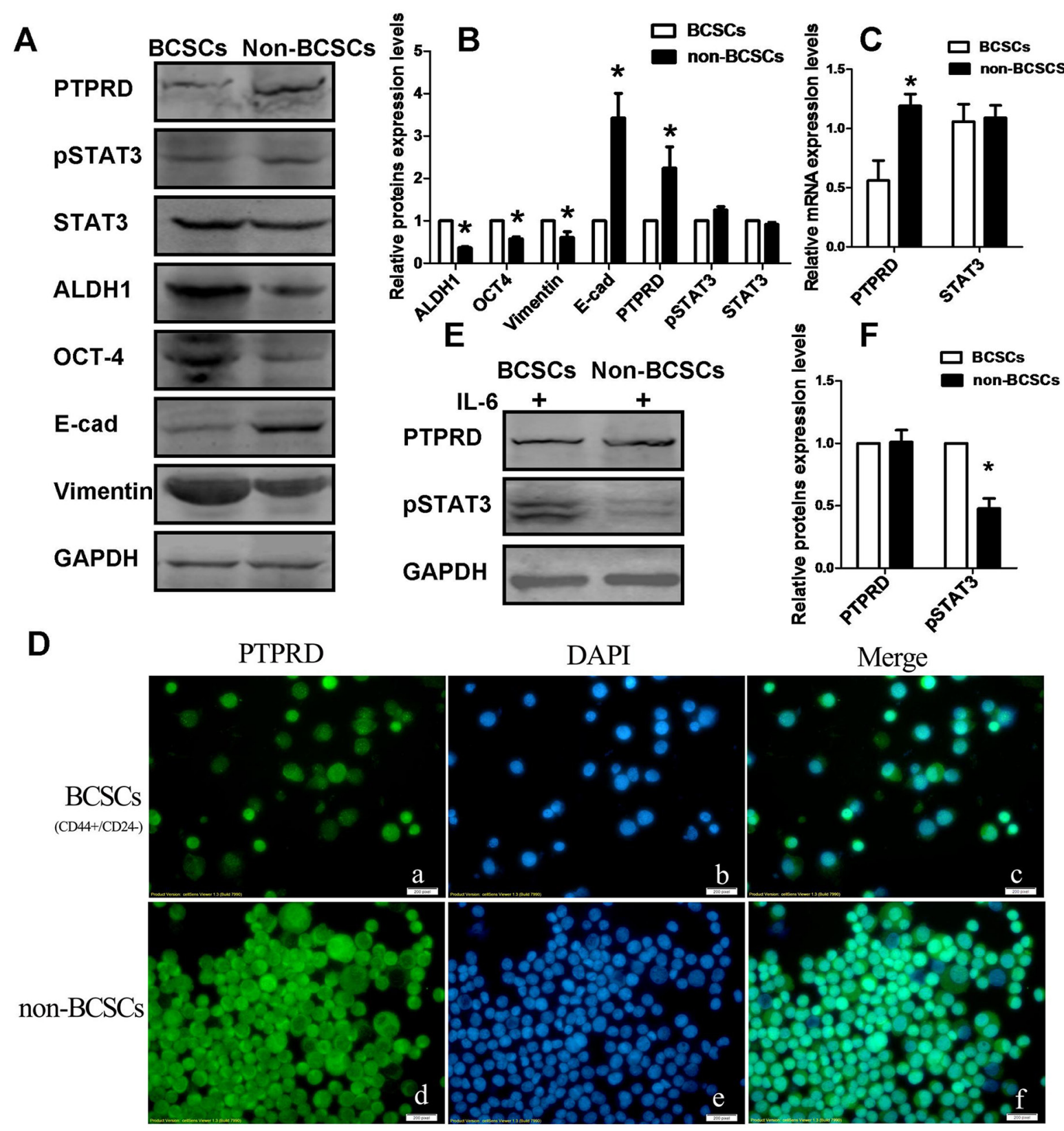

Figure 4: Endogenous PTPRD, STAT3, pSTAT3, E-cadherin, vimentin, ALDH1, and OCT4 levels in BCSCs and non-BCSCs. (A) Representative western blots. (B) Protein quantification from western blots like those shown in A ( $\left.{ }^{*} \mathrm{P}<0.05\right)$. (C) Quantification of mRNA in CD44 ${ }^{+} \mathrm{CD} 244^{-}$BCSCs and non-BCSCs using qRT-PCR ( $\left.{ }^{*} \mathrm{P}<0.05\right)$. (D) Immunofluorescence staining of PTPRD in serum-starved CD44 $/$ CD24- BCSCs and in non-BCSCs. (E) Western blotting analysis of PTPRD and pSTAT3 in BCSCs and non-BCSCs. MDA-MB-231 cells were stimulated with IL-6 for $12 \mathrm{~h}$ before separation of BCSCs and non-BCSCs. (F) Quantification of western blot experiments like those shown in $\mathrm{E}\left({ }^{*} \mathrm{P}<0.05\right)$. 
A

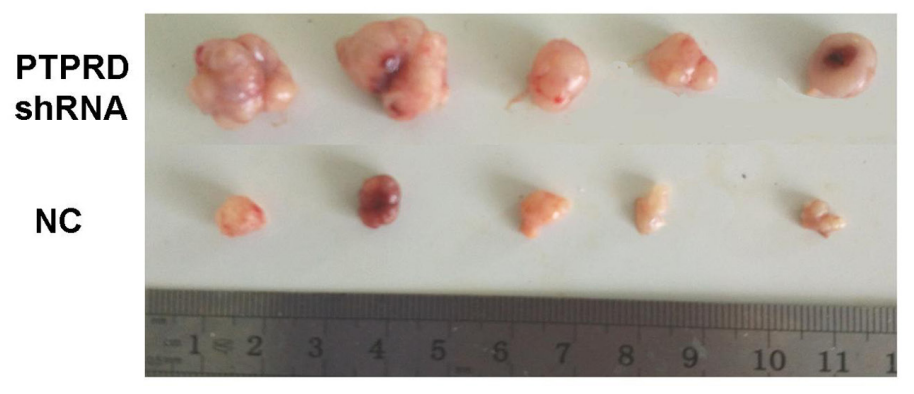

C

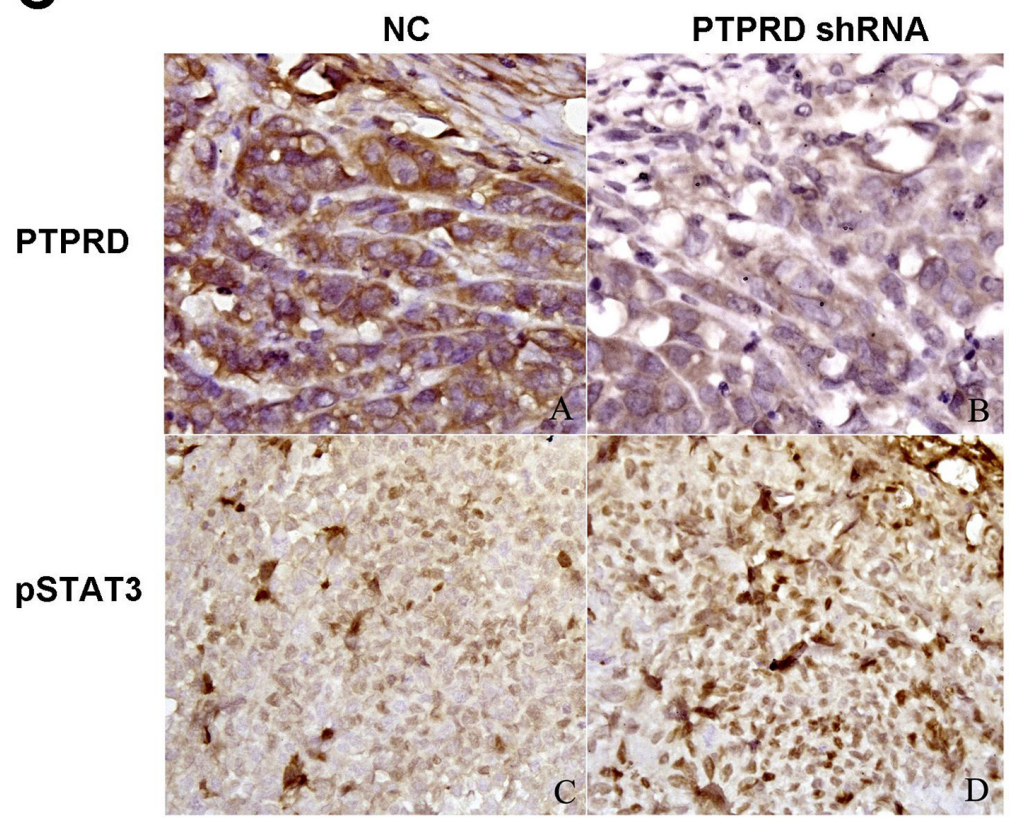

B

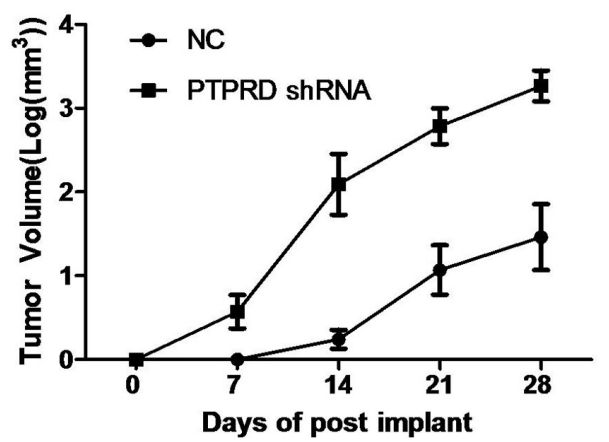

D

PTPRD

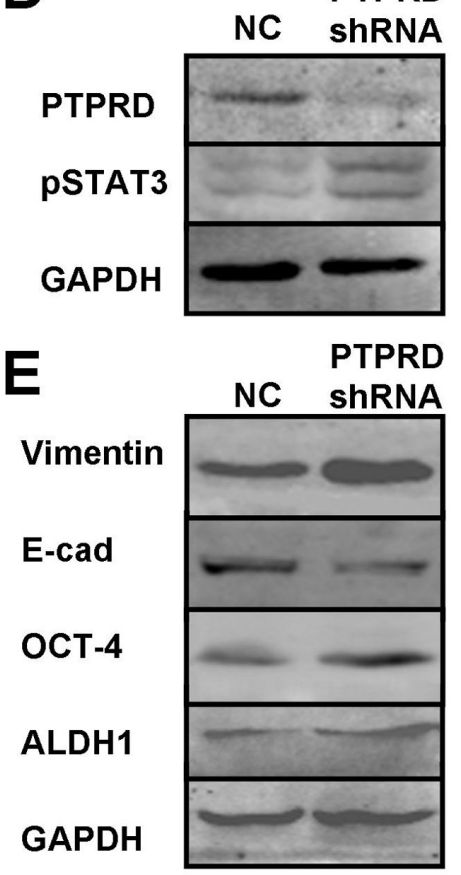

Figure 5: PTPRD knockdown promotes breast cancer cell xenograft formation and growth in nude mice. (A) Pictures of tumor xenografts excised from nude mice on day 28 post-implantation. (B) Tumor xenograft growth curves. Tumor size was measured every other day up to 28 days $(\mathrm{P}<0.05)$. Data are expressed as mean \pm SEM. (C) Immunohistochemical detection of PTPRD and pSTAT3 in tumor xenografts. (D) Western blot analysis of PTPRD and pSTAT3 in tumor xenografts. (E) Western blot analysis of E-cadherin, vimentin, ALDH1 and OCT-4 in tumor xenografts.

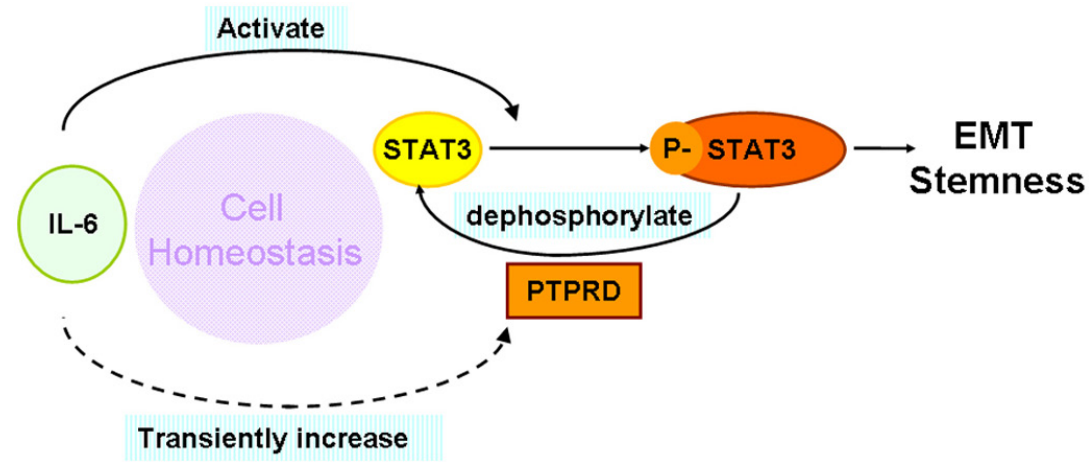

Figure 6: Model of the negative feedback circuit regulating the IL-6/STAT3 signaling pathway in breast cancer cells. IL-6 stimulation induces STAT3 activation, promoting EMT and stemness. In parallel, IL-6-induced PTPRD expression leads to STAT3 dephosphorylation to curb the overactivation of STAT3 signaling. Loss of PTPRD function in breast cancer cells leads to overactivation of STAT3 and promotes tumorigenesis. 
desmoplakin [16] and STAT3 [18]. STAT3 is an important regulator of stem cell maintenance and function [21, 23], and its dephosphorylation by PTPRD regulates its transcriptional activity in vitro $[12,18,35]$. The present study showed that PTPRD knockdown significantly increased STAT3 activation in vitro, and promoted tumorigenesis in mice characterized also by high pSTAT3 expression in tumor cells in vivo. This finding suggests that PTPRD dephosphorylates STAT3 in breast cancer cells in vivo.

CSCs are a unique subset of cancer cells with selfrenewal and a multilineage differentiation capacities [39]. Interestingly, we found that PTPRD expression is low in CD44 $/$ CD24- BCSCs compared with non-BCSCs within the same cell lines. Moreover, our experiments revealed that siRNA-mediated suppression of PTPRD expression enhanced CSC numbers and features, i.e. increased the CD $44^{+} / \mathrm{CD} 24{ }^{-}$subpopulation, enhanced mammosphere and holoclone forming ability, and stimulated the expression of the stem cell markers ALDH1 and OCT-4. Although a number of studies have reported or suggested a role for PTPRD in tumorigenesis [10-13, 16-18, 35], no direct evidence so far has associated PTPRD with stemness features. PTPRD belongs to the LAR subfamily of the LAR protein tyrosine phosphatase and is structurally and functionally similar to its members PTPo and LAR [40, 41]. Quarmyne et al. demonstrated that PTP $\sigma$ repressed proliferation of hematopoietic stem cells (HSCs). Compared with $P T P \sigma+/+$ cells, bone marrow cells from $P T P \sigma-/-$ mice displayed a marked increase in competitive repopulating capacity [42]. Furthermore, human РТРбHSCs had a 15-fold higher repopulating capacity than PTP $\sigma+$ HSCs [42]. Indeed, our current data suggest that PTPRD function in BCSCs is similar to that of PTP $\sigma$ on HSCs. We also detected high vimentin and low E-cadherin expression in BCSCs, consistent with findings from other studies showing that CSCs tend to have mesenchymal phenotypes [43-45].

Although PTPRD expression in BCSCs was lower than in non-BCSCs, to our surprise, pSTAT3 levels were similar in both populations. Several studies showed that STAT3 activation can promote stem cell-like properties in cancer cells [46-48]. It has been reported, also, that BCSCs exhibit higher levels of pSTAT3 [49]. The discrepancy between those and our own observations may be due to cell culture differences, as cells in this study were cultured in DMEM without FBS or cytokines for $24 \mathrm{~h}$ before isolation to eliminate possible effects of cytokines or growth factors on PTPRD and pSTAT3 expression. Thus, our experiments more likely reflect the basic status of STAT3 activation and PTPRD expression in quiescent BCSCs and non-BCSCs, without the influence of cytokines or growth factors. We reasoned that lower PTPRD expression in BCSCs might lead to enhanced STAT3 phosphorylation in response to IL-6, an assumption that proved to be true after measuring IL-6-induced pSTAT3 in both subpopulations. Therefore, our results suggested that in the quiescent state, STAT3 activation is similar in BCSCs and non-BCSCs, while under IL-6 stimulation, lower expression of the negative-feedback regulator PTPRD leads to stronger STAT3 activation in BCSCs.

In conclusion, we propose that PTPRD is an IL-6induced negative regulator of the IL-6/STAT3 signaling pathway (Figure 6). In normal cells, this feedback circuit contributes to the maintenance of cell homeostasis; in contrast, in cancer cells loss of PTPRD expression or function leads to STAT3 overactivation and promotion of tumorigenesis. Therapies aimed at restoring or enhancing PTPRD expression and/or activity may be effective in controlling breast cancer progression and metastasis.

\section{MATERIALS AND METHODS}

\section{Cell lines and culture}

The human breast cancer cell lines MDA-MB-231 and MCF-7 were obtained from the Cell Bank of Chinese Academy of Sciences (Shanghai, China) and cultured in DMEM/F12 medium (HyClone, Logan, UT, USA), supplemented with $10 \%$ fetal bovine serum (FBS; Gibco Laboratories, Grand Island, NY, USA) in a humidified incubator with $5 \% \mathrm{CO}_{2}$ at $37^{\circ} \mathrm{C}$.

To assess phenotypic and gene expression effects of IL-6, MDA-MB-231 and MCF-7 cells were cultured in serum-free medium containing $20 \mathrm{ng} / \mathrm{ml}$ of IL-6 (Cat \#200-06, Peprotech, Rocky Hill, NJ, USA) and harvested at $3,6,12,24$, and $48 \mathrm{~h}$. Cells cultured in serum-free medium without IL-6 were used as control.

\section{PTPRD siRNA transfection}

PTPRD-targeted and negative control (NC) siRNAs were synthesized by Invitrogen (Carlsbad, CA, USA). The siRNA oligonucleotides targeting PTPRD were as follows: (siRNA\#1, 5'-AUUGACAGCAACAACCCUGTT-3' and 5'-CAGGGUUGUUGCUGUCAAUTT-3'; siRNA\#2, 5'-UUUGAAGUUUAGUGGCUGCTT-3' and 5'-GCAGCCACUAAACUUCAAATT-3'; and SiRNA\#3, 5'-AUUUCAUGAUUAGUGGGUGTT-3' and 5'-CACCCACUAAUCAUGAAAUTT-3'). A short hairpin RNA (shRNA) expression plasmid (pGPHI/GFP/ Neo-PTPRD) was designed by GenePharma (Shanghai, China). After DNA sequence confirmation, plasmids (final concentration $=50 \mathrm{nM}$ ) were transfected into breast cancer cells using Lipofectamine 2000 (Invitrogen) according to the manufacturer's instructions.

\section{Immunofluorescence}

Cells were fixed in $4 \%$ paraformaldehyde, permeabilized with $100 \%$ ice-cold methanol, and incubated with $10 \%$ normal goat serum containing 
0.3\% Triton $^{\mathrm{TM}} \mathrm{X}-100$. After washing in Tris-based saline-Tween 20 (TBS-T), cells were incubated with a polyclonal anti-PTPRD antibody (LifeSpan BioSciences, Seattle, WA, USA) at a dilution of $1: 100$ at $4^{\circ} \mathrm{C}$ overnight, and subsequently with an FITC-conjugated secondary antibody (BioLegend, San Diego, CA, USA). Cell nuclei were counterstained with 4',6-diamidino-2-phenylindole (DAPI; Boster, Wuhan, China), and cells were then viewed under an Olympus BX41 fluorescence microscope and photographed using an Olympus DP72 camera (Olympus America, Central Valley, PA, USA).

\section{RNA isolation and quantitative RT-PCR (qRT- PCR)}

Total cellular RNA was isolated using TRIzol Reagent (Invitrogen) and reversely transcribed into cDNA using TransScript ${ }^{\circledR}$ One-Step gDNA Removal and cDNA Synthesis SuperMix (Tansgen Biotech, AT311, China) according to the manufacturers' instructions. The resulting cDNA samples were subjected to qPCR amplification using the SYBR Premix Ex Taq II (TaKaRa, Dalian, China) assay kit in a $20 \mu \mathrm{l}$ reaction mixture according to the manufacturer's instructions. The primers used were as follows: PTPRD, 5'-TCAGACAGACATTGCATCATCCAG-3' and 5'-GCCAAATGGGCAGTTATTGTTTC-3'; STAT3, 5'-CACATGCCACTTTGGTGTTTCA-3' and 5'-GGGCAATCTCCATTGGCTTC-3'; and GAPDH, 5'-GCACCGTCAAGGCTGAGAAC-3' and 5'-TGGTGAAGACGCCAGTGGA-3'. After amplification, all samples were normalized to the internal control (GAPDH) and fold changes were calculated using relative quantification $\left(\mathrm{RQ}=2^{-\Delta \Delta \mathrm{CT}}\right)$. The experiments were done in triplicate and repeated at least once.

\section{Protein extraction and western blot}

Total protein lysate from cells or tissues was prepared using standard RIPA lysis buffer (Sigma Chemicals, St. Louis, MO, USA). To minimize protein dephosphorylation, phosphatase-inhibitors (Santa Cruz Biotechnology, Santa Cruz, CA, USA) were added into the lysis buffer. Protein concentration was then measured using a bicinchoninic acid assay (Thermo Scientific, Bonn, Germany). Fifty to $80 \mu \mathrm{g}$ of each protein lysate was separated by $8-12 \%$ sodium dodecyl sulfate-polyacrylamide gel electrophoresis (SDS-PAGE) and transferred onto polyvinylidene fluoride (PVDF) membranes (Millipore, Billerica, MA, USA). Membranes were then blocked in 5\% skim milk solution in TBST for $1 \mathrm{~h}$ at room temperature and then incubated with primary antibodies raised against PTPRD (1:500; LifeSpan BioSciences), ALDH1 (1:300; Proteintech Group, Chicago, USA), STAT3 antibody (1:500; Proteintech
Group), pSTAT3 (Tyr705) (1:500; Cell Signaling Technology, Inc., Danvers, MA, USA), OCT-4 (1:300; Proteintech Group), E-cadherin (1:500; Proteintech Group), and vimentin (1:500; Proteintech Group) at $4^{\circ} \mathrm{C}$ overnight, and subsequently with an IRDye $800 \mathrm{CW}$ labeled secondary antibody $(1: 5,000)$. Protein bands were quantified by optical density analysis and normalized to GAPDH.

\section{Wound-healing assay}

After gene transfection, cells were grown to $70 \%$ $80 \%$ confluence in $6-\mathrm{cm}$ cell culture dishes, and cell monolayers were scratched across the center using a $10 \mu l$ pipette tip. Cells were washed with DMEM twice and then cultured in DMEM without FBS for up to $72 \mathrm{~h}$. Images were captured using an Olympus IX73 microscope connected to an Olympus DP73 camera at 0, 24, 48, and $72 \mathrm{~h}$.

\section{Tumor cell migration and invasion assays}

To analyze breast cancer cell invasion capacity, cell inserts $(8.0 \mu \mathrm{m}$ pore size membrane; Corning, Corning, NY, USA) were coated with $100 \mu \mathrm{l}$ Matrigel (BD Bioscience, San Jose, CA, USA) diluted 1:3 in DMEM (for invasion assays), or left untreated (for migration assays). Subsequently, $2 \times 10^{4}$ cells, previously cultured in low FBS $(0.1 \%)$ medium for $24 \mathrm{~h}$, were seeded onto cell inserts in the upper chambers in serum-free medium. The lower chamber was filled with $0.5 \mathrm{ml}$ DMEM containing $10 \%$ FBS. After culturing for $24 \mathrm{~h}$, migrating or invading cells in the lower surface of the membranes were fixed with methanol, stained with $0.01 \%$ crystal violet and photographed. Results represent the average number of cells in 5 fields per membrane in triplicate inserts.

\section{Isolation of $\mathrm{CD}^{+} 4^{+} / \mathrm{CD}^{-} 4^{-}$breast cancer stem cells}

MDA-MB231 cells were starved for $24 \mathrm{~h}$ in DMEM/F12 without FBS and dissociated into single-cell suspensions using $2.5 \%$ trypsin followed by centrifugation at $300 \mathrm{~g}$ for $5 \mathrm{~min}$. Cell pellets were resuspended in $40 \mu \mathrm{l}$ of PBE suspension buffer (for approximately $1 \times 10^{7}$ cells) and incubated with CD24 microbeads (CD24 Microbead Kit; Miltenyi Biotec, Bergisch Gladbach, Germany) followed by a magnetic separation. CD24- cells were collected, washed, and incubated with CD44 microbeads (Miltenyi Biotec) at $4{ }^{\circ} \mathrm{C}$ for $15 \mathrm{~min}$. After washing and resuspension in $500 \mu \mathrm{l}$ of $\mathrm{PBE}$ buffer, magnetic separation was used for enrichment of CD $44^{+} / \mathrm{CD} 24^{-}$cells. To detect the effect of IL-6 on STAT3 signaling in BCSCs and non-BCSCs, before isolation MDA-MB-231 cells were cultured in DMEM for $24 \mathrm{~h}$ and then cultured again in DMEM/F12 containing $20 \mathrm{ng} / \mathrm{ml}$ of IL-6. 


\section{Tumor cell colony formation assay}

BCSCs were isolated using magnetic beads and seeded into 6-well plates in triplicate at a density of 500 cells/well. After culturing for 14 days in complete medium (changed every 3 days), the cells were fixed with methanol and stained with $0.1 \%$ crystal violet. Cultures were then photographed and cell colonies were counted and measured using Image-Pro Plus image analysis software (Media Cybernetics, Inc., Rockville, MD, USA).

\section{Mammosphere formation assay}

After transfection with PTPRD siRNA or NC siRNA for $24 \mathrm{~h}$, BCSCs were isolated, inoculated into ultra-low attachment 6-well plates (Corning) at a density of $4 \times 10^{4}$ cells/well, and grown in DMEM/F12 supplemented with B27 (1:50, Invitrogen), $20 \mathrm{ng} / \mathrm{ml}$ human recombinant EGF (Sigma-Aldrich), $20 \mathrm{ng} / \mathrm{ml} \mathrm{bFGF} \mathrm{(Sigma-Aldrich),} 4 \mu \mathrm{g} /$ $\mathrm{ml}$ heparin (Sigma-Aldrich), and $5 \mu \mathrm{g} / \mathrm{ml}$ insulin (SigmaAldrich) for 14 days. Cell colonies larger than $60 \mu \mathrm{m}$ in diameter were counted under an inverted microscope (Olympus Corporation, Tokyo, Japan).

\section{Flow cytometry analysis of the $\mathrm{CD}^{+} 4^{+} / \mathrm{CD}^{-} 4^{-}$cell population}

After isolation, cells were diluted at a density of $10^{6}$ cells $/ \mathrm{ml}$ and incubated with anti-human CD44-FITC and CD24-PE antibodies (BioLegend, San Diego, CA, USA) at $4^{\circ} \mathrm{C}$ for $30 \mathrm{~min}$. Flow cytometric analysis was performed using a FACSCalibur Flow Cytometer (BD, Franklin Lakes, NJ, USA).

\section{Cell viability assay}

Cell viability was measured using the Cell Counting Kit-8 (CCK-8) assay kit (Dojindo, Kumamoto, Japan). In brief, cells were transfected with PTPRD siRNA or NC siRNA for $24 \mathrm{~h}$ and then sub-cultured for up to $72 \mathrm{~h}$. At the end of each experiment, $10 \mu \mathrm{l}$ of CCK-8 solution was added into each well and the cells were further incubated at $37^{\circ} \mathrm{C}$ for $2 \mathrm{~h}$. Absorbance was measured in a microplate reader at $450 \mathrm{~nm}$. DMEM/F12 was used as a blank control. Proliferation data were expressed as \% of NC control.

\section{Mouse xenograft model}

Animal experiments and procedures were approved by the Animal Care and Use Committee of Dalian Medical University and performed in accordance with the Guide for the Care and Use of Laboratory Animals (NIH). Ten severe combined immunodeficiency (SCID) mice were randomly divided into two groups. Negative control shRNA (shRNA-NC) or PTPRD shRNA-transfected MDA-MB-231 cells $\left(5 \times 10^{5}\right)$ were resuspended in 100 $\mu \mathrm{l}$ phosphate buffered saline (PBS) and injected into mammary fat pads. Tumor volumes (V) were monitored and recorded every other day. On day 28 after tumor cell inoculation, mice were sacrificed and tumors were excised and analyzed by immunohistochemistry and western blotting.

\section{Statistical analysis}

All in vitro experiments were performed in triplicate and repeated at least three times. Data were expressed as mean value \pm standard error (SEM). Statistical analysis was performed using SPSS version 19.0 (SPSS, Chicago, IL, USA) or GraphPad Prism 5 (GraphPad Software, La Jolla, CA, USA). All other data were analyzed using unpaired two-tailed Student's $t$-test. $P<0.05$ was considered statistically significant.

\section{Ethical approval}

This study was reviewed and approved by the Ethical Committee and Institutional Review Board of Dalian Medical University.

\section{Abbreviations}

BCSC: breast cancer stem cells; CSC: cancer stem cells; PTPRD: Receptor-type tyrosine-protein phosphatase $\delta$; PTP: protein tyrosine phosphatase; STAT3: Signal transducer and activator of transcription 3; IL-6: interleukin-6; CD44: cluster of differentiation 44, standard isoform; CD24: cluster of differentiation 24, standard isoform; CSC: cancer stem cell; EGFR: epidermal growth factor receptor; EMT: epithelialmesenchymal transition; FGF: fibroblast growth factor; HGF/SF: hepatocyte growth factor/scatter factor; shRNA: small hairpin ribonucleic acid; siRNA: small interference ribonucleic acid; ALDH1: aldehyde dehydrogenase 1; OCT-4: Octamer-binding transcription factor-4.

\section{Author contributions}

Xiaotang $\mathrm{Yu}$ and Lianhong $\mathrm{Li}$ conceived and designed the experiments and drafted the manuscript. Xiaotang Yu, Fan Zhang, Shujun Fan, Jiazhi Li, Chunying Zhang, Ying Lu, and Qing Li conducted the experiments. Jun Mao, Wei Ma, and Bo Wang performed all statistical analyses. Lianhong $\mathrm{Li}$ and $\mathrm{Bo}$ Song discussed and revised the manuscript. All authors read and approved the final version of this manuscript before submission.

\section{ACKNOWLEDGMENTS}

We would like to thank Dr. Hui Wang of the Flow Cytometry and Cell Sorting Core, Dalian Medical University (Dalian, China) for technical assistance. 


\section{CONFLICTS OF INTEREST}

The authors declare that they have no conflicts of interest to disclose.

\section{FUNDING}

This work was supported by a grant from the National Natural Science Foundation of China (\#81272430).

\section{REFERENCES}

1. Torre LA, Bray F, Siegel RL, Ferlay J, Lortet-Tieulent J, Jemal A. Global cancer statistics, 2012. CA Cancer J Clin. 2015; 65:87-108. https://doi.org/10.3322/caac.21262.

2. Kang Y, Siegel PM, Shu W, Drobnjak M, Kakonen SM, Cordon-Cardo C, Guise TA, Massague J. A multigenic program mediating breast cancer metastasis to bone. Cancer Cell. 2003; 3:537-49.

3. Garner JM, Fan M, Yang CH, Du Z, Sims M, Davidoff AM, Pfeffer LM. Constitutive activation of signal transducer and activator of transcription 3 (STAT3) and nuclear factor kappaB signaling in glioblastoma cancer stem cells regulates the Notch pathway. J Biol Chem. 2013; 288:26167-76. https://doi.org/10.1074/jbc. M113.477950.

4. Luo M, Brooks M, Wicha MS. Epithelial-mesenchymal plasticity of breast cancer stem cells: implications for metastasis and therapeutic resistance. Curr Pharm Des. 2015; 21:1301-10.

5. Moncharmont C, Levy A, Gilormini M, Bertrand G, Chargari C, Alphonse G, Ardail D, Rodriguez-Lafrasse C, Magne N. Targeting a cornerstone of radiation resistance: cancer stem cell. Cancer Lett. 2012; 322:139-47. https://doi. org/10.1016/j.canlet.2012.03.024.

6. Chen D, Bhat-Nakshatri P, Goswami C, Badve S, Nakshatri H. ANTXR1, a stem cell-enriched functional biomarker, connects collagen signaling to cancer stem-like cells and metastasis in breast cancer. Cancer Res. 2013; 73:5821-33. https://doi.org/10.1158/0008-5472.can-13-1080.

7. Kim RK, Uddin N, Hyun JW, Kim C, Suh Y, Lee SJ. Novel anticancer activity of phloroglucinol against breast cancer stem-like cells. Toxicol Appl Pharmacol. 2015; 286:143-50. https://doi.org/10.1016/j.taap.2015.03.026.

8. Lin CY, Barry-Holson KQ, Allison KH. Breast cancer stem cells: are we ready to go from bench to bedside? Histopathology. 2016; 68:119-37. https://doi.org/10.1111/ his. 12868 .

9. Chagnon MJ, Uetani N, Tremblay ML. Functional significance of the LAR receptor protein tyrosine phosphatase family in development and diseases. Biochem Cell Biol. 2004; 82:664-75. https://doi.org/10.1139/ o04-120.
10. Acun T, Demir K, Oztas E, Arango D, Yakicier MC. PTPRD is homozygously deleted and epigenetically downregulated in human hepatocellular carcinomas. OMICS. 2015; 19:220-9. https://doi.org/10.1089/omi.2015.0010.

11. Wang D, Wang L, Zhou J, Pan J, Qian W, Fu J, Zhang G, Zhu Y, Liu C, Wang C, Jin Z, He Z, Wu J, et al. Reduced expression of PTPRD correlates with poor prognosis in gastric adenocarcinoma. PLoS One. 2014; 9:e113754. https://doi.org/10.1371/journal.pone.0113754.

12. Peyser ND, Du Y, Li H, Lui V, Xiao X, Chan TA, Grandis JR. Loss-of-Function PTPRD Mutations Lead to Increased STAT3 Activation and Sensitivity to STAT3 Inhibition in Head and Neck Cancer. PLoS One. 2015; 10:e0135750. https://doi.org/10.1371/journal.pone.0135750.

13. Du Y, Su T, Tan X, Li X, Xie J, Wang G, Shen J, Hou J, Cao G. Polymorphism in protein tyrosine phosphatase receptor delta is associated with the risk of clear cell renal cell carcinoma. Gene. 2013; 512:64-9. https://doi.org/10.1016/j. gene.2012.09.094.

14. Li X, Tan X, Yu Y, Chen H, Chang W, Hou J, Xu D, Ma L, Cao G. D9S168 microsatellite alteration predicts a poor prognosis in patients with clear cell renal cell carcinoma and correlates with the down-regulation of protein tyrosine phosphatase receptor delta. Cancer. 2011; 117:4201-11. https://doi.org/10.1002/cncr.26028.

15. Cancer Genome Atlas Network. Cancer Genome Atlas Network. Comprehensive molecular portraits of human breast tumours. Nature. 2012; 490:61-70. https://doi. org/10.1038/nature11412.

16. Walia V, Prickett TD, Kim JS, Gartner JJ, Lin JC, Zhou M, Rosenberg SA, Elble RC, Solomon DA, Waldman T, Samuels Y. Mutational and functional analysis of the tumorsuppressor PTPRD in human melanoma. Hum Mutat. 2014; 35:1301-10. https://doi.org/10.1002/humu.22630.

17. Funato K, Yamazumi Y, Oda T, Akiyama T. Tyrosine phosphatase PTPRD suppresses colon cancer cell migration in coordination with CD44. Exp Ther Med. 2011; 2:457-63. https://doi.org/10.3892/etm.2011.231.

18. Ortiz B, Fabius AW, Wu WH, Pedraza A, Brennan CW, Schultz N, Pitter KL, Bromberg JF, Huse JT, Holland EC, Chan TA. Loss of the tyrosine phosphatase PTPRD leads to aberrant STAT3 activation and promotes gliomagenesis. Proc Natl Acad Sci U S A. 2014; 111:8149-54. https://doi. org/10.1073/pnas.1401952111.

19. Chan TA, Glockner S, Yi JM, Chen W, Van Neste L, Cope L, Herman JG, Velculescu V, Schuebel KE, Ahuja $\mathrm{N}$, Baylin SB. Convergence of mutation and epigenetic alterations identifies common genes in cancer that predict for poor prognosis. PLoS Med. 2008; 5:e114. https://doi. org/10.1371/journal.pmed.0050114.

20. Budczies J, Bockmayr M, Denkert C, Klauschen F, Lennerz JK, Gyorffy B, Dietel M, Loibl S, Weichert W, Stenzinger A. Classical pathology and mutational load of breast cancer - integration of two worlds. J Pathol Clin Res. 2015; 1:22538. https://doi.org/10.1002/cjp2.25. 
21. Marotta LL, Almendro V, Marusyk A, Shipitsin M, Schemme J, Walker SR, Bloushtain-Qimron N, Kim JJ, Choudhury SA, Maruyama R, Wu Z, Gonen M, Mulvey LA, et al. The JAK2/STAT3 signaling pathway is required for growth of CD44(+)CD24(-) stem cell-like breast cancer cells in human tumors. J Clin Invest. 2011; 121:2723-35. https://doi.org/10.1172/jci44745.

22. Shostak K, Chariot A. NF-kappaB, stem cells and breast cancer: the links get stronger. Breast Cancer Res. 2011; 13:214. https://doi.org/10.1186/bcr2886.

23. Chung SS, Aroh C, Vadgama JV. Constitutive activation of STAT3 signaling regulates hTERT and promotes stem celllike traits in human breast cancer cells. PLoS One. 2013; 8:e83971. https://doi.org/10.1371/journal.pone.0083971.

24. Zhong Z, Wen Z, Darnell JE Jr. Stat3: a STAT family member activated by tyrosine phosphorylation in response to epidermal growth factor and interleukin-6. Science. 1994; 264:95-8.

25. Bishop JL, Thaper D, Zoubeidi A. The Multifaceted Roles of STAT3 Signaling in the Progression of Prostate Cancer. Cancers (Basel). 2014; 6:829-59. https://doi.org/10.3390/ cancers6020829.

26. Resemann HK, Watson CJ, Lloyd-Lewis B. The Stat3 paradox: a killer and an oncogene. Mol Cell Endocrinol. 2014; 382:603-11. https://doi.org/10.1016/j. mce.2013.06.029.

27. Tremblay ML. On the role of tyrosine phosphatases as negative regulators of STAT signaling in breast cancers: new findings and future perspectives. Breast Cancer Res. 2013; 15:312. https://doi.org/10.1186/bcr3437.

28. Yu XT, Zhu SN, Xu ZD, Hu XQ, Zhu TF, Chen JQ, Lu SL. Roles of EGFR-Stat3 signal pathway in carcinogenesis of experimental hepatoma in rats. J Cancer Res Clin Oncol. 2007; 133:145-52. https://doi.org/10.1007/ s00432-006-0139-z.

29. Malanga D, De Marco C, Guerriero I, Colelli F, Rinaldo N, Scrima M, Mirante T, De Vitis C, Zoppoli P, Ceccarelli M, Riccardi M, Ravo M, Weisz A, et al. The Akt1/IL-6/STAT3 pathway regulates growth of lung tumor initiating cells. Oncotarget. 2015; 6:42667-86. https://doi.org/10.18632/ oncotarget.5626.

30. An H, Kim JY, Oh E, Lee N, Cho Y, Seo JH. Salinomycin Promotes Anoikis and Decreases the CD44+/CD24- StemLike Population via Inhibition of STAT3 Activation in MDA-MB-231 Cells. PLoS One. 2015; 10:e141919. https://doi.org/10.1371/journal.pone.0141919.

31. Saadin K, White IM. Breast cancer stem cell enrichment and isolation by mammosphere culture and its potential diagnostic applications. Expert Rev Mol Diagn. 2013; 13:49-60. https://doi.org/10.1586/erm.12.117.

32. Tan L, Sui X, Deng H, Ding M. Holoclone forming cells from pancreatic cancer cells enrich tumor initiating cells and represent a novel model for study of cancer stem cells. PLoS One. 2011; 6:e23383. https://doi.org/10.1371/journal. pone. 0023383 .
33. Alonso A, Sasin J, Bottini N, Friedberg I, Friedberg I, Osterman A, Godzik A, Hunter T, Dixon J, Mustelin T. Protein tyrosine phosphatases in the human genome. Cell. 2004; 117:699-711. https://doi.org/10.1016/j. cell.2004.05.018.

34. Nair P, De Preter K, Vandesompele J, Speleman F, Stallings RL. Aberrant splicing of the PTPRD gene mimics microdeletions identified at this locus in neuroblastomas. Genes Chromosomes Cancer. 2008; 47:197-202. https://doi. org/10.1002/gcc.20521.

35. Veeriah S, Brennan C, Meng S, Singh B, Fagin JA, Solit DB, Paty PB, Rohle D, Vivanco I, Chmielecki J, Pao W, Ladanyi M, Gerald WL, et al. The tyrosine phosphatase PTPRD is a tumor suppressor that is frequently inactivated and mutated in glioblastoma and other human cancers. Proc Natl Acad Sci U S A. 2009; 106:9435-40. https://doi. org/10.1073/pnas.0900571106.

36. Kohno T, Otsuka A, Girard L, Sato M, Iwakawa R, Ogiwara H, Sanchez-Cespedes M, Minna JD, Yokota J. A catalog of genes homozygously deleted in human lung cancer and the candidacy of PTPRD as a tumor suppressor gene. Genes Chromosomes Cancer. 2010; 49:342-52. https://doi. org/10.1002/gcc.20746.

37. Micalizzi DS, Ford HL. Epithelial-mesenchymal transition in development and cancer. Future Oncol. 2009; 5:1129-43. https://doi.org/10.2217/fon.09.94.

38. Pang MF, Georgoudaki AM, Lambut L, Johansson J, Tabor V, Hagikura K, Jin Y, Jansson M, Alexander JS, Nelson CM, Jakobsson L, Betsholtz C, Sund M. TGF-beta1-induced EMT promotes targeted migration of breast cancer cells through the lymphatic system by the activation of CCR7/ CCL21-mediated chemotaxis. Oncogene. 2016; 35:748-60. https://doi.org/10.1038/onc.2015.133.

39. Geng SQ, Alexandrou AT, Li JJ. Breast cancer stem cells: Multiple capacities in tumor metastasis. Cancer Lett. 2014; 349:1-7. https://doi.org/10.1016/j.canlet.2014.03.036.

40. Pulido R, Serra-Pages C, Tang M, Streuli M. The LAR/ PTP delta/PTP sigma subfamily of transmembrane proteintyrosine-phosphatases: multiple human LAR, PTP delta, and PTP sigma isoforms are expressed in a tissue-specific manner and associate with the LAR-interacting protein LIP.1. Proc Natl Acad Sci U S A. 1995; 92:11686-90.

41. Schaapveld RQ, Schepens JT, Robinson GW, Attema J, Oerlemans FT, Fransen JA, Streuli M, Wieringa B, Hennighausen L, Hendriks WJ. Impaired mammary gland development and function in mice lacking LAR receptorlike tyrosine phosphatase activity. Dev Biol. 1997; 188:13446. https://doi.org/10.1006/dbio.1997.8630.

42. Quarmyne M, Doan PL, Himburg HA, Yan X, Nakamura M, Zhao L, Chao NJ, Chute JP. Protein tyrosine phosphatasesigma regulates hematopoietic stem cell-repopulating capacity. J Clin Invest. 2015; 125:177-82. https://doi. org/10.1172/jci77866.

43. Lin J, Liu X, Ding D. Evidence for epithelial-mesenchymal transition in cancer stem-like cells derived from carcinoma 
cell lines of the cervix uteri. Int J Clin Exp Pathol. 2015; 8:847-55.

44. Morata-Tarifa C, Jimenez G, Garcia MA, Entrena JM, Grinan-Lison C, Aguilera M, Picon-Ruiz M, Marchal JA. Low adherent cancer cell subpopulations are enriched in tumorigenic and metastatic epithelial-to-mesenchymal transition-induced cancer stem-like cells. Sci Rep. 2016; 6:18772. https://doi.org/10.1038/srep18772.

45. Xue J, Zhu Y, Sun Z, Ji R, Zhang X, Xu W, Yuan X, Zhang B, Yan Y, Yin L, Xu H, Zhang L, Zhu W, et al. Tumorigenic hybrids between mesenchymal stem cells and gastric cancer cells enhanced cancer proliferation, migration and stemness. BMC Cancer. 2015; 15:793. https://doi.org/10.1186/ s12885-015-1780-1.

46. Civenni G, Longoni N, Costales P, Dallavalle C, Garcia Inclan C, Albino D, Nunez LE, Moris F, Carbone GM, Catapano CV. EC-70124, a novel glycosylated indolocarbazole multi-kinase inhibitor, reverts tumorigenic and stem cell properties in prostate cancer by inhibiting STAT3 and NF-kappaB. Mol Cancer Ther. 2016. https:// doi.org/10.1158/1535-7163.mct-15-0791.

47. Bak Y, Kwon T, Bak IS, Hong J, Yu DY, Yoon DY. IL-32 $\theta$ inhibits stemness and epithelial-mesenchymal transition of cancer stem cells via the STAT3 pathway in colon cancer. Oncotarget. 2016; 7:7307-17. https://doi.org/10.18632/ oncotarget.7007.

48. Hajimoradi M, Mohammad Hassan Z, Ebrahimi M, Soleimani M, Bakhshi M, Firouzi J, Samani FS. STAT3 is Overactivated in Gastric Cancer Stem-Like Cells. Cell J. 2016; 17:617-28.

49. Lin L, Hutzen B, Lee HF, Peng Z, Wang W, Zhao C, Lin HJ, Sun D, Li PK, Li C, Korkaya H, Wicha MS, Lin J. Evaluation of STAT3 signaling in ALDH+ and ALDH+/ CD44+/CD24- subpopulations of breast cancer cells. PLoS One. 2013; 8:e82821. https://doi.org/10.1371/journal. pone. 0082821 . 